\title{
Surgery for clival lesions: open resection versus the expanded endoscopic endonasal approach
}

\author{
Giorgio Carrabba, M.D., Amir R. Dehdashti, M.D., and Fred Gentili, M.D., F.R.C.S.C. \\ Division of Neurosurgery, University Health Network, Toronto Western Hospital, University of Toronto, \\ Ontario, Canada
}

\begin{abstract}
Object. Clival lesions pose significant challenges with regard to their surgical management. The expanded endoscopic endonasal (EEE) approach is a promising minimally invasive technique for lesions of the central skull base. The authors' aim in the current paper was to discuss the surgical treatment of clival lesions and to present the technical details, indications, and limitations of the EEE approach. Data from a recent endoscopically treated group will be compared with findings in a previous cohort of patients treated via classic open anterior and lateral approaches.

Methods. Since June 2005, 17 patients with clival lesions underwent surgery via the EEE approach. Suitable candidates were chosen according to lesion characteristics, clinical parameters, and surgical goals. Neurological outcomes, Karnofsky Performance Scale scores, the extent of lesion resection, and complications were evaluated among these patients. Eighteen percent of the patients in the endoscopic group presented with recurrent disease. Another series of 43 patients, who had undergone resection of clival lesions via an anterior (rhinotomy, maxillectomy, microscopic transsphenoidal surgery, or transoral surgery) or lateral (pterional, frontoorbitozygomatic, or combined suprainfratentorial retrosigmoid) approach, was similarly reviewed. Twenty-three of these patients (53\%) presented with recurrent disease and thus had undergone prior surgery.

Results. Following the EEE approach, 11 (79\%) of 14 patients who had presented with neurological symptoms experienced improvement, and gross-total resection was achieved in 59\% of the patients and subtotal removal in $41 \%$. Complications included CSF leakage (24\%), tension pneumocephalus (6\%), and intracranial hematoma (6\%). The patient with the latter complication was the only one who experienced permanent neurological worsening.

In the open resection group, neurological worsening occurred in $33 \%$ of the patients (14 of 43). Total and grosstotal removals were achieved in $84 \%$ of patients and subtotal removal in $14 \%$.

Conclusions. The EEE approach has been shown to be a safe and effective technique for the resection of clival lesions with limited lateral extension. The choice of surgical approach must be tailored according to both patient and tumor characteristics. Although the 2 patient series featured in this paper are not comparable-because of a selection bias-higher rates of neurological morbidity and total and gross-total resections were observed in the open resection group. Given the long survival of some patients, the EEE approach should be favored whenever reasonable. (DOI: $10.3171 /$ FOC .2008.25.12.E7)
\end{abstract}

KEY WORDS $\bullet \quad$ chordoma $\bullet \quad$ clivus $\bullet \quad \begin{aligned} & \text { endoscopic resection } \\ & \text { expanded endoscopic endonasal approach } \\ & \text { transsphenoidal approach }\end{aligned}$

$\mathrm{L}$ ESIONS of the clivus, rare and of varied pathology, continue to pose significant challenges to neurosurgeons. ${ }^{1}$ Their deep location in the midline and their intimate relationship to critical neurovascular structures often make total removal difficult. Therapy options include biopsy procedure, partial resection, or radical resection with or without various forms of radiotherapy.

Chordomas and chondrosarcomas are among the most common histopathologies and traditionally have been treated with extensive resections. ${ }^{1}$ This practice is based on the fact that the extent of tumor removal appears to be correlated with long-term prognosis. ${ }^{1,7,8,10,20,24,31,45,46,51,58}$ Never-

Abbreviations used in this paper: $\mathrm{EEE}=$ expanded endoscopic endonasal; KPS = Karnofsky Performance Scale. theless, despite aggressive surgical therapy, which can be associated with serious morbidity, these tumors display aggressive behavior, infiltrating bone, being relatively radioresistant, and having a tendency to recur on long-term follow-up. ${ }^{1}$ Among other pathologies, meningiomas also affect the clivus, often by extension, but given their different biological characteristics and more benign nature, they have not been analyzed in this report.

The central skull base can be approached via multiple surgical routes, which are classified into anterior and lateral approaches. Anterior approaches include the bifrontal transbasal craniotomy, ${ }^{55}$ transsphenoidal and extended transsphenoidal routes, ${ }^{9,40,41}$ lateral rhinotomy (with partial, total, or extended maxillectomy), ${ }^{27,34}$ transoral and transpalatal techniques, ${ }^{11,17}$ transfacial approach 


\section{G. Carrabba, A. R. Dehdashti, and F. Gentili}

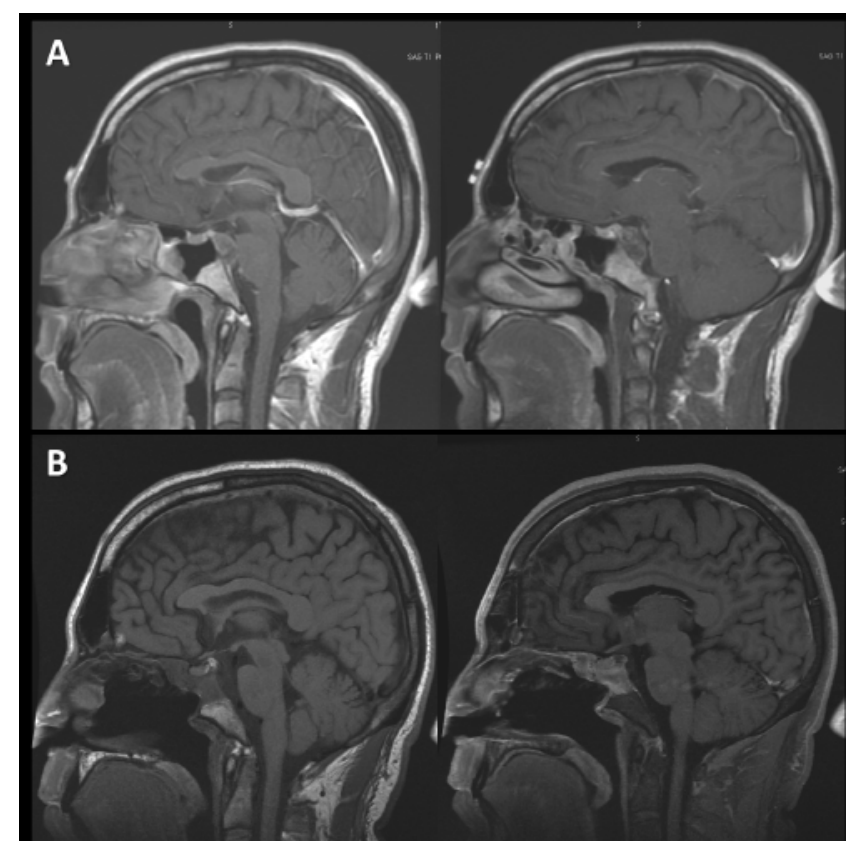

FIG. 1. Images obtained in a 37-year-old patient who underwent surgery for a low-grade chondrosarcoma of the clivus. Clinically the patient had a cranial nerve VI palsy on the right side, which completely resolved after resection via an EEE approach. Notably, this patient was discharged 3 days after surgery without any complication. Intraoperative endoscopic views from this case are shown in Fig. 3. A: Preoperative midline sagittal T1-weighted Gd-enhanced MR images showing a lesion affecting the upper and middle part of the clivus. Mild brainstem compression is noted without significant lateral extension. These characteristics made the patient an optimal candidate for the EEE approach. B: Sagittal T1-weighted Gd-enhanced MR images obtained 3 months postsurgery, showing complete resection.

(LeFort I maxillotomy), ${ }^{18,35,49}$ and anterior cervical decompression and fusion. ${ }^{6,60}$ The lateral approaches comprise the pterional, frontoorbitozygomatic, ${ }^{61}$ infratemporal, ${ }^{54,57}$ transpetrosal, $3,30,44,53$ combined suprainfratentorial retrosigmoid, ${ }^{25,63}$ and far lateral suboccipital. ${ }^{2,56}$ For larger tumors, combined and staged procedures have also been proposed. ${ }^{61}$

The increasing use of the endoscope in transsphenoidal surgery ${ }^{4,14,15,37}$ and its application to other lesions of the skull base have opened another chapter in skull base surgery. The versatility of this minimally invasive technique has widened the boundaries of the pituitary fossa to include regions far beyond the sellar floor., $5,12,13,16,21-23$, $29,36,42,47,48,52,59,62$ Using the expanded endonasal approach, one can readily access, in a minimally invasive way, the entire central skull base from the frontal sinus anteriorly to the clivus and region of the foramen magnum and odontoid process inferiorly.,12,19 Proponents of these more minimally invasive endoscopic approaches cite less morbidity and equal or better resection rates..$^{14-16,21-23,29}$ In this report, we present the anatomical and technical nuances of the purely EEE approach for the treatment of clival lesions, describe our surgical experience and results in a series of 17 patients, and compare our findings with those in a previous series of 43 patients who had undergone well-established transcranial techniques.

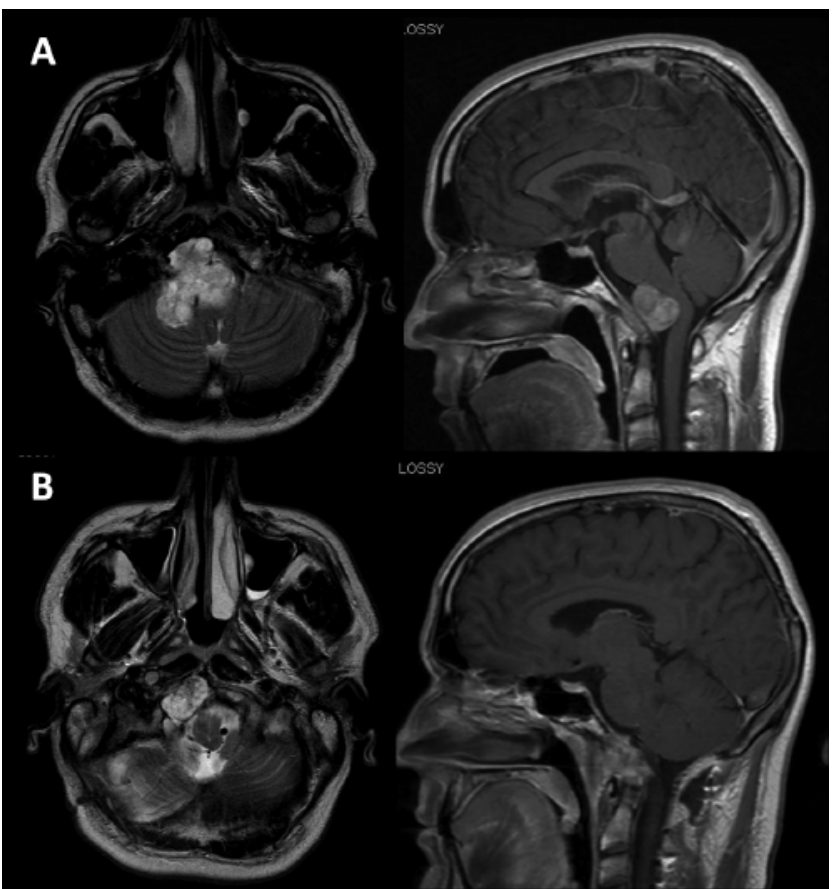

FIG. 2. Preoperative and postoperative MR images obtained in a 39-year-old patient who underwent a combined approach for a clival chordoma. The patient presented with headache and neck pain but without neurological deficits. The first procedure was a suprainfratentorial retrosigmoid approach (preoperative images shown in A), which was chosen for the significant posterolateral and inferior extension of the tumor and for the marked brainstem compression. After this procedure, an EEE approach was performed to achieve a complete resection of the tumor (preoperative images shown in B). No neurological worsening, CSF leakage, or other complications were observed after this combined procedure. A: Preoperative axial T2-weighted (left) and midline sagittal T1-weighted Gd-enhanced (right) MR images showing a lesion affecting the middle and lower part of the clivus with a significant posterolateral extension to the right side. Marked brainstem compression is also visible. These characteristics and the patient's age and good neurological status indicated aggressive resection via a suprainfratentorial restrosigmoid approach followed by an EEE approach. B: Axial T2-weighted (left) and midline sagittal T1-weighted Gd-enhanced (right) MR images obtained after the first operation, revealing lesion remnants in the midline or its proximity and greatly reduced brainstem compression. At this point, complete tumor removal was achieved via the EEE approach (data not shown).

\section{Methods}

\section{Patients and Surgical Approaches}

Between June 2005 and June 2008, 17 patients (10 males and 7 females, with a median age of 48 years) underwent a purely EEE approach for a variety of clival lesions. Among this group were 12 chordomas, 2 ossifying fibromas, 1 chondrosarcoma, 1 osteogenic sarcoma, and 1 case of malignant otitis externa involving the clivus. The average time from the onset of symptoms to diagnosis of the disease was 8 months. The patients' preoperative symptoms are summarized in Table 1. Briefly, the majority of patients (12 of 17) presented with diplopia or dysphagia related to cranial nerve deficits, based on a lesion location in either the middle/upper clivus or the lower clivus. An illustrative case of a lesion involving the upper 


\section{Endoscopic versus open resections for clival lesions}

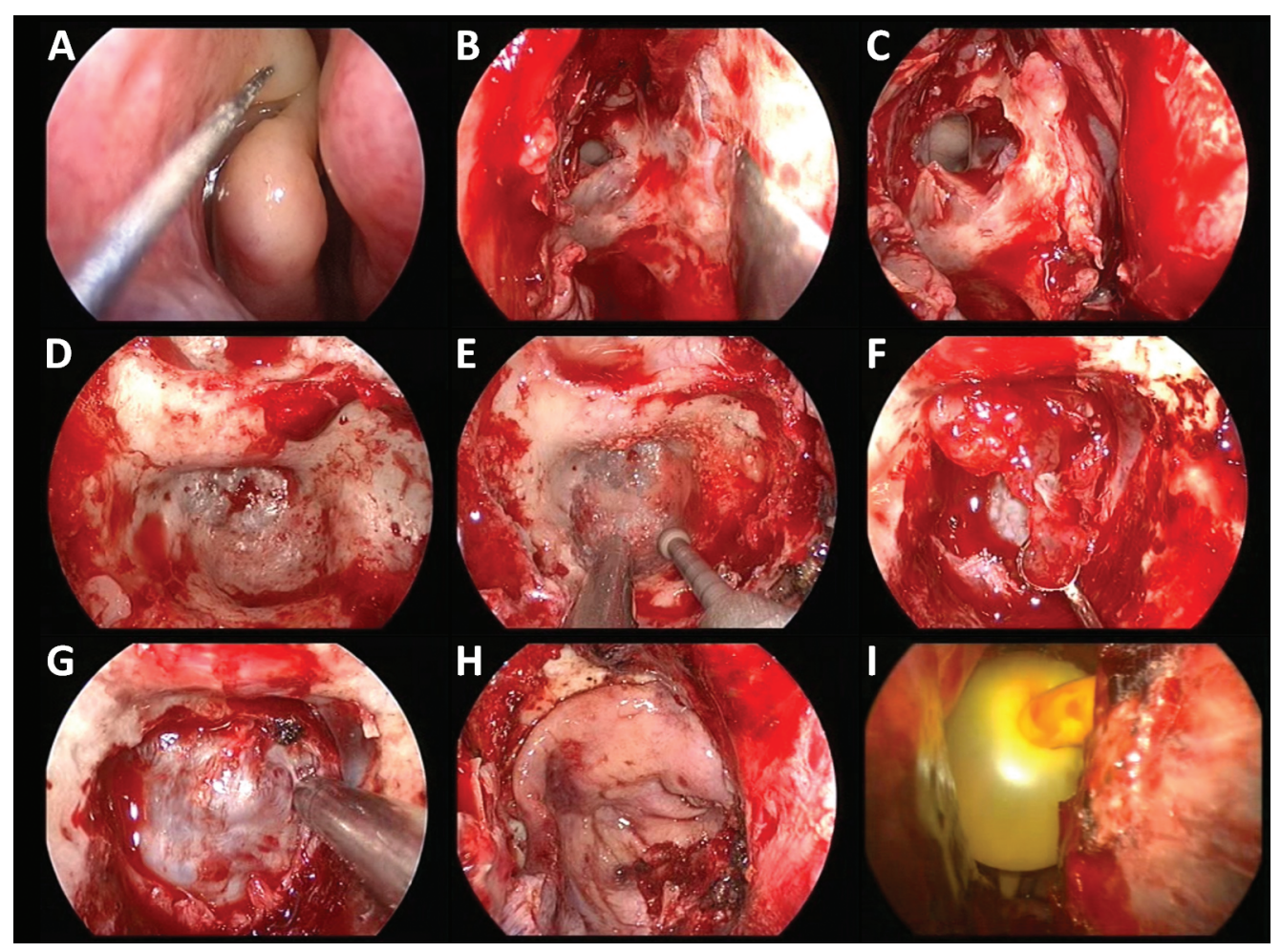

FIG. 3. Endoscopic views featuring the surgical steps for resection of a clival lesion via the EEE approach. A: Infiltration with epinephrine 1:100,000 at the base of the right middle turbinate prior to performing a turbinectomy. B: Initial fracture of the posterior part of the septum, which allows exposure of the sphenoid rostrum and permits work with 2 instruments through the 2 nostrils (bimanual technique). C: Exposure of sphenoid rostrum, a fundamental landmark always located in the midline. The sphenoid ostium has already been enlarged and permits a view inside the sphenoid sinus. D: Panoramic view of the sellar and clival area. Note that the clivus in its upper part is eroded by the neoplasm. The clival carotid arteries are visible lateral to the clivus. E: Drilling of the clivus. The middle part of the clivus, below the tumor erosion, is drilled to allow full exposure of the neoplasm. F: Epidural tumor removal. The lesion is removed with the help of various curettes. The dura mater is visible in the background. G: View after having performed complete resection of the tumor. Note that the dura was not violated by the tumor in this case. $\mathrm{H}$ : Reconstruction with a pedicled septal mucosa flap. This flap is part of the outlay reconstruction, which is also done with a fascia lata graft (underneath the mucosa flap), fibrin glue, and Gelfoam. I: Foley catheter placement to favor the repair through the maintenance of a gentle pressure. The catheter is removed after $3-4$ days.

midline clivus is featured in Fig. 1. Brainstem symptoms were seen in only 2 patients who had previously undergone surgery and received radiation therapy. Three patients presented with headache.

Two patients had undergone staged procedures with a prior lateral craniotomy for large cranial base chordomas with significant lateral extension; preoperative MR images obtained in 1 of these patients are featured in Fig. 2 . Two patients had undergone a lateral rhinotomy 8 and 10 years previously, and 1 patient had undergone a microscopic transsphenoidal surgery 7 years before the present recurrence. All 3 patients (18\%) with recurrent tumors had received radiation following their initial treatment. None of the newly diagnosed cases had been treated with radiotherapy prior to surgery. The technical details of the EEE approach have been described elsewhere, ${ }^{16}$ but the most significant steps of the procedure are detailed below and shown in Fig. 3.

Prior to June 2005, 43 patients with clival lesions (23 chordomas and 20 chondrosarcomas) underwent surgery via classic skull base approaches: 14 patients (33\%) through an anterior approach (lateral rhinotomy with maxillectomy, transsphenoidal route, or transoral route) and 29 patients $(67 \%$ ) via a lateral approach. The preferred technique was the combined suprainfratentorial retrosigmoid approach, which was used in 23 patients (53\%); a pterional or frontoorbitozygomatic craniotomy was performed in 6 patients (14\%). None of these approaches will be described as they have already been the subject of numerous other publications. . $3,11,18,27,30,34,35,41,49,53-57,61,63^{2}$

Among these 43 patients, 19 (44\%) were female, and the median age of the entire group was 43.7 years. The median duration of symptoms was 6.8 months. Twentythree patients $(53 \%)$ had undergone prior surgery (2 months -4 years).

\section{Technical Description of the EEE Procedure}

Each patient was placed supine with the head slightly more flexed than for a common endoscopic procedure for a sellar lesion, to improve the field of view toward the clivus. Neuronavigation was used routinely (Stealth, Medtronic). A $0^{\circ}, 4-\mathrm{mm}$ endoscope $18 \mathrm{~cm}$ in length was used to perform the procedure (Karl Storz GmbH \& Co. KG). Angled scopes were rarely needed. 
G. Carrabba, A. R. Dehdashti, and F. Gentili

TABLE 1: Summary of pre- and postoperative symptoms in 17 patients who underwent the EEE approach for clival lesions*

\begin{tabular}{|c|c|c|c|}
\hline $\begin{array}{l}\text { No. of } \\
\text { Patients }\end{array}$ & Preop Symptoms & Postop Symptoms (no. of cases) & Notes \\
\hline 7 & CN VI deficit & full recovery, 5 ; partial recovery, 1 ; stable deficit, 1 & \\
\hline 1 & CN VI deficit \& optic nerve compression & $\begin{array}{l}\text { stable CN VI deficit \& partial recovery of the visual } \\
\text { field deficit }\end{array}$ & \\
\hline 3 & lower $\mathrm{CN}$ deficits & partial recovery, 2; worsening condition, 1 & \\
\hline 1 & decreased hearing & partial recovery & $\begin{array}{l}\text { malignant otitis } \\
\text { externa }\end{array}$ \\
\hline 1 & brainstem compression & partial recovery of hemiparesis & \\
\hline 1 & brainstem compression \& lower $\mathrm{CN}$ deficit & new hemiparesis \& worsening of $\mathrm{CN}$ deficit & $\begin{array}{l}\text { postop hema- } \\
\text { toma }\end{array}$ \\
\hline 3 & headache & improved/resolved, 3 & \\
\hline
\end{tabular}

A binostril bimanual technique was used routinely and allowed instrument maneuverability identical to that available with the microsurgical approach. In the majority of cases, both middle turbinates were resected (Fig. $3 \mathrm{~A})$, although on occasion the removal of 1 turbinate with lateral subluxation of the contralateral turbinate was sufficient. The posterior half of the nasal septum including the maxillary crest was removed to widely expose the sphenoid rostrum (Fig. 3B and C). The sphenoid rostrum is an important landmark, invariably located in the midline. After cauterizing both posterior nasal branches of the sphenopalatine arteries, the sphenoid sinus was widely opened and the sphenoid floor drilled down to the nasopharynx and clivus. Laterally, the sphenoid floor was resected to allow visualization of the lateral recess. This wide exposure of the sphenoid floor is crucial and allows a greater field of view and placement of the endoscope so that it does not interfere with the bimanual technique and maneuverability of instruments used by the surgeon.

At the end of the exposure, the lateral recess of the sphenoid, the opticocarotid recess, and the clivocarotid protuberances become important surgical landmarks for the remainder of the procedure (Fig. 3D). At this point, the tumor often is visible, especially if the clivus is eroded anteriorly. Drilling was usually started from the upper part of the clivus (Fig. 3E). Although the medial wall of the clival carotid artery can be removed with slight retraction of the carotid artery laterally, the clival carotid arteries represent the lateral limit of the clival exposure. The lower floor of the sphenoid was drilled further down to allow access to the middle and lower clivus. Further inferiorly, the preclival fascia can be opened with a midline incision and reflected laterally. Occasionally, the tumor may have eroded the dura with an intradural extension. In such cases the dura is opened in the midline in a linear fashion to allow exposure of the intradural component of the tumor. The tumor is then removed under endoscopic guidance by using the same bimanual microsurgical tech- nique applied during an open microscopic resection, but with a significantly wider and better-illuminated field of view (Fig. 3F and G).

In cases of tumor extension to the upper clivus, the EEE approach allows resection of the sellar floor and exposure of the dorsum sella.

Reconstruction is a key step in the procedure and critical to avoid complications, the most troublesome being CSF leakage and meningitis. A multilayer technique was preferred. First, a single layer of Surgicel (Johnson \& Johnson Gateway) or Duragen (Integra LifeSciences Corp.) was positioned as an inlay and reinforced by an autogenous fascia lata graft (always as an intradural inlay). A layer of fascia lata was then placed extradurally (outlay) to cover the dural and osseous edges. A thin layer of fibrin glue or Bioglue was used at the edges, and fat was applied to cover the outlay fascia. More recently, we have begun to use a local vascularized nasal flap of septal mucosa (based on the posterior septal artery), which was added over the outlay fascia lata (Fig. $3 \mathrm{H}) .{ }^{26}$ Fibrin glue and Gelfoam (Pfizer) were used to cover the whole reconstruction. On completion of the repair, a 14 Fr Foley catheter was positioned to apply gentle pressure and keep in place the multilayer reconstruction. The Foley catheter was removed after 3-4 days.

\section{Results}

\section{Expanded Endoscopic Endonasal Resection Group}

Among the 8 patients who had presented with a preoperative cranial nerve VI palsy, 5 recovered completely after surgery, 1 showed a partial recovery, and 2 remained unchanged. Interestingly, in the 1 case with a cranial nerve VI palsy and chiasm compression, a partial improvement in vision without any change in the abducent nerve palsy was observed. Among the 3 patients with a lower cranial nerve deficit, 2 experienced improvement after surgery 


\section{Endoscopic versus open resections for clival lesions}

and 1 showed a worsening condition. The patient with malignant otitis externa and bilateral progressive hearing loss had moderate improvement after surgery. In the patient with brainstem compression and long-tract signs, dramatic improvement was observed after surgery. In a patient with a preoperative lower cranial nerve deficit and brainstem compression from a recurrent extensive chordoma, a hematoma developed postoperatively, necessitating reexploration and clot removal. This patient exhibited a new hemiparesis and worsening of the lower cranial nerve deficit requiring a temporary tracheostomy. In retrospect, an aggressive attempt to remove a significant lateral extension of the tumor from a midline approach likely contributed to the complication.

The extent of tumor removal was evaluated on the basis of surgical findings and postoperative MR imaging data obtained immediately and 3 months after surgery. Gross-total resection was defined during surgery as complete macroscopic tumor removal and at the 3-month MR imaging follow-up as absent enhancement. However, we believe that even in satisfactory cases, some microscopic cells were probably left behind in bone, especially in chordoma cases. Therefore, keeping in mind that gross-total removal does not mean curative resection, we achieved gross-total resection in 10 cases $(59 \%)$ and subtotal resection $(>80 \%)$ in $7(41 \%)$. A large tumor size and extensive osseous involvement, lateral extension of the lower part of the tumor, scarred tissue in recurrent cases, and surgery for tissue diagnostics were the main reasons to perform subtotal resections.

The most serious complication was a postoperative hematoma (1 patient [6\%]) with the onset of new neurological deficits (hemiparesis). Hydrocephalus also developed in that case, necessitating temporary external ventricular drainage. Four patients demonstrated CSF leakage (24\%); 2 of them responded well to lumbar drainage and 2 required reexploration and repeated reconstruction of the skull base with the multilayer closure technique, followed by lumbar drainage for 5 days, with successful results. One patient $(6 \%)$ had tension pneumocephalus and needed bur hole evacuation. No deaths were observed in this group of patients. Note that none of the 7 patients with a vascularized nasal septal flap experienced CSF leakage.

The immediate postoperative KPS score was 100 in 15 cases $(88 \%)$. The only patients who had a lower score included 1 with a hemorrhagic complication (KPS score of 70) and 1 with preoperative brainstem symptoms (KPS score of 80$)$. Notably, 3 patients (18\%) had an improved score after surgery. The hospital stay ranged from 3 to 24 days (median 8 days). Follow-up periods ranged from 4 to 26 months (median 16 months). There was no tumor regrowth or recurrence at the time of this short-term follow-up (median 16 months).

Our recent protocol for the postoperative treatment of chordomas is conformal intensity-modulated radiotherapy, which was started or scheduled in all cases between 2 and 6 weeks after surgery, except in the 3 patients who had undergone prior radiotherapy.

\section{Open Resection Group}

Complete tumor removal was achieved in only 3 pa- tients $(7 \%)$. Gross-total removal was realized in 33 patients $(77 \%)$, subtotal in $6(14 \%)$, and partial in $1(2 \%)$.

The overall postoperative morbidity rate was 33\% (14 patients) and was attributable to new neurological deficits (8 cases), worsening of presenting symptoms (5 cases), and wound infection without meningitis (1 case). New neurological deficits consisted of cranial nerve deficits in 5 patients $(12 \%)$ and brainstem compression symptoms in $3(7 \%)$. Of the 5 patients who experienced a deterioration of presenting symptoms, 3 had worsening of lower cranial nerve deficits and 2 had an aggravation of the preexisting hemiparesis.

The mortality rate was $2 \%$ ( 1 patient) and was attributable to a vascular injury of the brainstem.

The postoperative KPS score was 100 in 17 patients (40\%), 90 in 12 (28\%), 80 in 10 (23\%), and 40 in $3(7 \%)$.

At a mean follow-up of 5.4 years, 4 patients ( 3 harboring chordomas and 1 a chondrosarcoma) died of uncontrolled tumor progression between 3.5 and 19 years after the initial diagnosis. A difference in progressionfree survival was noted between cases of chordomas and chondrosarcomas: 60 and $95 \%$, respectively.

Further details for this group are not presented as they are beyond the scope of this report.

\section{Discussion}

\section{Current State of the Art in Surgical Approaches for Clival Lesions}

With regard to surgical approaches, a variety of craniotomies, standard transsphenoidal and transoral approaches, or a combination have been advocated for clival lesions. ${ }^{1,61}$ The choice of surgical route depends on a number of factors including the location and main extension of the tumor as well as the experience and comfort level of the surgeon. Because clival tumors are generally midline tumors that displace the neuraxis dorsally or dorsolaterally, anterior midline approaches, such as the transbasal extended frontal, ${ }^{55}$ transsphenoidal, ${ }^{9,40,41}$ transmaxillary, ${ }^{34}$ midfacial degloving, ${ }^{49}$ and transoral, ${ }^{11}$ are generally preferred. However, lateral extension of clival lesions to the parasellar region, petrous bone, and occipital condyle requires a lateral approach to the clivus that can be combined with an anterior approach. 3,44,55-57,61

Chordomas are by far the most common tumors arising from the clivus. ${ }^{38,43}$ Emanating from remnants of the notochord, chordomas exhibit slow expansile growth with infiltration and destruction of bone as well as compression of adjacent neurovascular structures. ${ }^{28}$ Although typically extradural, these lesions can invade the dura and extend intradurally. ${ }^{50}$ The location and pattern of growth make curative resection rarely possible. ${ }^{1}$ While radical resection should be the goal when feasible-as the extent of tumor removal has been a positive prognosticator for chordomas-aggressive resections have been associated with significant morbidity. 1,7,8,20,24,31,51,58 Radiation therapy in any form (conventional, stereotactic, Gamma Knife, or proton beam) plays an effective but adjuvant role. ${ }^{31,32}$

Although chondrosarcomas often involve the clivus, patients with these lesions typically present with more 


\section{G. Carrabba, A. R. Dehdashti, and F. Gentili}

lateral extensions, which are not ideal indications for purely midline approaches, and thus transcranial routes are often preferred. . $^{10,45,58}$

A minimally invasive technique, such as the EEE approach, is appealing as it exploits an anatomical corridor (nasal cavities and sinuses) to reach deep-seated structures without the need for craniotomy and brain retraction and their associated morbidity. An endoscope allows a significantly wider and better-illuminated field of view. A binostril bimanual technique permits the use of a microsurgical technique, as is performed in open procedures. Note that there are some disadvantages to the EEE approach, including a limited working space, reduced maneuverability, and the need for special instrumentation. There is also a significant learning curve with the procedure. The narrow midline approach can also limit the possibility of achieving more extensive resections, particularly when dealing with lesions with significant lateral extension such as in chondrosarcomas. In our experience, lesions with significant lateral extension beyond the cavernous sinuses or clival carotid arteries or with marked posterolateral extension are thought to be unsuitable for the EEE approach alone. These lesions often require a staged approach combining a craniotomy with an endoscopic technique. The choice of an open approach for lateral extensions-whether pterional, frontoorbitozygomatic, infratemporal, transpetrosal, retrosigmoid, or far lateral-is made in general according to surgeon preferences and tumor characteristics. ${ }^{1,61}$ A combined open and endoscopic approach may offer the advantage of decreasing the morbidity associated with traditional open approaches, giving the surgeon an opportunity to deal with the different components of the tumor in the most appropriate and direct way.

For purely midline clival lesions, we have come to favor the expanded endoscopic approach. It minimizes the morbidity associated with more invasive and aggressive approaches, is better tolerated by the patient, and can be used to achieve similar degrees of resection. The use of this approach for clival chordomas and other lesions involving the clivus has evolved over the last couple of decades through microscopic and extended techniques. ${ }^{9}, 12,19,41$ Jho has described an endoscopic approach to clival lesions with good results. ${ }^{37}$ Cappabianca et al. ${ }^{5}$ and Solares et al. ${ }^{59}$ have also described the technique and its feasibility in a group of patients with different parasellar and clival pathologies. Kingdom and Delgaudio ${ }^{39}$ have reported results from a series of 10 clival lesions approached endoscopically. A pathological diagnosis was obtained in all cases and included adenocarcinoma, cholesterol granuloma, plasmacytoma, metastases (liposarcoma and renal cell carcinoma), fibrous dysplasia, meningoencephalocele, and teratoma. Recently, Frank et al. ${ }^{22}$ have reported their experience in a series of 11 patients harboring chordomas (9 cases) and chondrosarcomas (2 cases) of the cranial base. These authors have concluded that the endoscopic approach is an important adjunct to craniotomy for the treatment of such lesions.

Our preliminary results confirmed the possibility of achieving satisfactory resections through a purely endoscopic endonasal procedure. All patients in our series of
17 had total or subtotal tumor removal, as confirmed on MR imaging performed 3 months after surgery. These data are comparable to those obtained following open resection, as borne out by our series of 43 patients. In 2 cases $(12 \%)$ in the present endoscopic series, radical tumor removal was achieved through a combined approach. It is our belief that the overall good results in terms of tumor removal via the EEE approach derive in part from the careful selection of patients as appropriate candidates. The choice of an approach was made according to the degree of lateral extension as well as other factors such as size and location of the lesion, presence of brainstem compression, vessel involvement, and the overall objective of surgery. As our experience with the EEE approach for purely midline lesions has increased, it has become our preferred method and an alternative to the open transcranial or transfacial approaches. It has resulted in lower morbidity and a shorter hospital stay (data not shown). Nonetheless, the endoscope remains only a tool, and factors such as previous surgery and/or radiation therapy will limit the possibility of radical removal as they do in open procedures. Moreover, larger clival lesions with significant lateral or posterior extension often require the use of a combined approach.

Postoperative neurological morbidity was low following the EEE approach. In addition, 11 (79\%) of the 14 patients with preoperative neurological deficits had improvement, 1 (14\%) had a stable deficit, and only 2 (14\%) had a worsened condition. Only 1 patient $(6 \%)$ had significant neurological worsening, and this patient had harbored a large recurrent chordoma and had undergone multiple open resections and radiation therapy. In retrospect, our attempts to resect the lateral extension of the tumor were inappropriate for an endoscopic approach.

For many reasons, including a selection bias and the duration of follow-up, it is impossible to compare the 2 featured series. Nonetheless, our results indicated that the EEE approach is associated with lower overall neurological complications (rates of morbidity 11\%, and mortality $0 \%$ ) as compared with the classic open resection procedure (rates of morbidity $33 \%$, and mortality $2 \%$ ). The ability to achieve total lesion removal is comparable and more related to the infiltrative nature of the lesions than the type of approach.

In terms of oncological control of the disease, good long-term results were achieved in the open resection group; and in keeping with results in the literature, chordomas had a worse prognosis than chondrosarcomas. ${ }^{24,32,33,58}$ Although the absence of any early recurrences in the EEE group has been encouraging, the limited median followup (16 months) does not allow any definite conclusion as to whether the technique can decrease long-term recurrence.

Pathologies other than chordomas are quite rare, as noted in our series, and no definitive conclusion can be made with regard to the benefits of the EEE approach except that it allowed a minimally invasive approach with very low morbidity.

As with endoscopic resection of craniopharyngiomas, ${ }^{23} \mathrm{CSF}$ leakage still represents a major problem when performing this type of expanded approach. In our 


\section{Endoscopic versus open resections for clival lesions}

series $24 \%$ of patients (4 of 17) had CSF leakage postoperatively, which resolved with lumbar drainage in $50 \%$ of cases. Fifty percent of the patients required a second operation. We believe that the routine use of a pedicled septal mucosal flap will significantly reduce this complication. Indeed, none of the last 7 patients with this type of reconstruction had a CSF leak. Multiple surgical procedures and prior radiation therapy remain significant risk factors for CSF leakage as seen in 2 of 4 patients in our series with this profile.

We believe that traditional transcranial approaches will continue to have a significant place in the surgical armamentarium for dealing with clival lesions. It is important to carefully select the most appropriate approach for each patient. The indications for open versus expanded endoscopic resection depend on a variety of factors including patient- and tumor-related factors as well as the experience of the surgeon. A realistic surgical objective (extensive resection, conservative resection, or biopsy procedure) must be defined and management carefully tailored to the individual patient.

In terms of the evolving use of the EEE approach, it is ideal for obtaining a tissue diagnosis for any lesion in this area.

Lastly, we emphasize that the endoscopic resection of clival lesions requires specific endoscopic instrumentation and expertise.

\section{Conclusions}

The fully EEE approach is a valid alternative to transcranial or transoral operations in the treatment of clival lesions. The main indications for the approach include a centrally located neoplasm or as an adjunct to craniotomy for more extensive tumors. Its minimally invasive nature makes it very attractive in select cases, with the potential for minimizing the morbidity associated with other extensive approaches and maximizing patient comfort. Early results suggest at least an equivalency with other techniques, although long-term outcomes have yet to be analyzed. This approach should be part of the armamentarium of skull base surgeons and considered as an important option for the treatment of carefully selected clival tumors.

\section{References}

1. al-Mefty O, Borba LA: Skull base chordomas: a management challenge. J Neurosurg 86:182-189, 1997

2. Babu RP, Sekhar LN, Wright DC: Extreme lateral transcondylar approach: technical improvements and lessons learned. J Neurosurg 81:49-59, 1994

3. Blevins NH, Jackler RK, Kaplan MJ, Gutin PH: Combined transpetrosal-subtemporal craniotomy for clival tumors with extension into the posterior fossa. Laryngoscope 105:975982, 1995

4. Cappabianca P, Cavallo LM, de Divitiis E: Endoscopic endonasal transsphenoidal surgery. Neurosurgery 55:933-941, 2004

5. Cappabianca P, Cavallo LM, Esposito F, De Divitiis O, Messina A, De Divitiis E: Extended endoscopic endonasal approach to the midline skull base: the evolving role of transsphenoidal surgery. Adv Tech Stand Neurosurg 33:151-199, 2008
6. Cloward RB, Passarelli P: Removal of giant clival chordoma by an anterior cervical approach. Surg Neurol 11:129-134, 1979

7. Colli B, Al-Mefty O: Chordomas of the craniocervical junction: follow-up review and prognostic factors. J Neurosurg 95:933-943, 2001

8. Colli BO, Al-Mefty O: Chordomas of the skull base: followup review and prognostic factors. Neurosurg Focus 10(3):E1, 2001

9. Couldwell WT, Weiss MH, Rabb C, Liu JK, Apfelbaum RI, Fukushima T: Variations on the standard transsphenoidal approach to the sellar region, with emphasis on the extended approaches and parasellar approaches: surgical experience in 105 cases. Neurosurgery 55:539-550, 2004

10. Crockard HA, Cheeseman A, Steel T, Revesz T, Holton JL, Plowman N, et al: A multidisciplinary team approach to skull base chondrosarcomas. J Neurosurg 95:184-189, 2001

11. Crockard HA, Sen CN: The transoral approach for the management of intradural lesions at the craniovertebral junction: review of 7 cases. Neurosurgery 28:88-98, 1991

12. de Divitiis E, Cappabianca P, Cavallo LM: Endoscopic transsphenoidal approach: adaptability of the procedure to different sellar lesions. Neurosurgery 51:699-707, 2002

13. de Divitiis E, Cavallo LM, Esposito F, Stella L, Messina A: Extended endoscopic transsphenoidal approach for tuberculum sellae meningiomas. Neurosurgery 61:229-238, 2007

14. Dehdashti AR, Ganna A, Karabatsou K, Gentili F: Pure endoscopic endonasal approach for pituitary adenomas: early surgical results in 200 patients and comparison with previous microsurgical series. Neurosurgery 62:1006-1007, 2008

15. Dehdashti AR, Gentili F: Current state of the art in the diagnosis and surgical treatment of Cushing disease: early experience with a purely endoscopic endonasal technique. Neurosurg Focus 23(3):E9, 2007

16. Dehdashti AR, Karabatsou K, Ganna A, Witterick I, Gentili F: Expanded endoscopic endonasal approach for clival chordomas. Neurosurgery 63:299-309, 2008

17. Delgado TE, Garrido E, Harwick RD: Labiomandibular, transoral approach to chordomas in the clivus and upper cervical spine. Neurosurgery 8:675-679, 1981

18. DeMonte F, Diaz E Jr, Callender D, Suk I: Transmandibular, circumglossal, retropharyngeal approach for chordomas of the clivus and upper cervical spine. Technical note. Neurosurg Focus 10(3):E10, 2001

19. Dusick JR, Esposito F, Kelly DF, Cohan P, DeSalles A, Becker DP, et al: The extended direct endonasal transsphenoidal approach for nonadenomatous suprasellar tumors. J Neurosurg 102:832-841, 2005

20. Forsyth PA, Cascino TL, Shaw EG, Scheithauer BW, O'Fallon JR, Dozier JC, et al: Intracranial chordomas: a clinicopathological and prognostic study of 51 cases. J Neurosurg 78:741747, 1993

21. Frank G, Pasquini E, Doglietto F, Mazzatenta D, Sciarretta V, Farneti G, et al: The endoscopic extended transsphenoidal approach for craniopharyngiomas. Neurosurgery 59:75-83, 2006

22. Frank G, Sciarretta V, Calbucci F, Farneti G, Mazzatenta D, Pasquini E: The endoscopic transnasal transsphenoidal approach for the treatment of cranial base chordomas and chondrosarcomas. Neurosurgery 59 (1 Suppl):ONS50-ONS57, 2006

23. Gardner PA, Kassam AB, Snyderman CH, Carrau RL, Mintz $\mathrm{AH}$, Grahovac S, et al: Outcomes following endoscopic, expanded endonasal resection of suprasellar craniopharyngiomas: a case series. J Neurosurg 109:6-16, 2008

24. Gay E, Sekhar LN, Rubinstein E, Wright DC, Sen C, Janecka IP, et al: Chordomas and chondrosarcomas of the cranial base: results and follow-up of 60 patients. Neurosurgery 36:887897,1995 


\section{G. Carrabba, A. R. Dehdashti, and F. Gentili}

25. Goel A, Muzumdar D: Conventional posterior fossa approach for surgery on petroclival meningiomas: a report on an experience with 28 cases. Surg Neurol 62:332-340, 2004

26. Hadad G, Bassagasteguy L, Carrau RL, Mataza JC, Kassam A, Snyderman $\mathrm{CH}$, et al: A novel reconstructive technique after endoscopic expanded endonasal approaches: vascular pedicle nasoseptal flap. Laryngoscope 116:1882-1886, 2006

27. Harsh G, Ojemann R, Varvares M, Swearingen B, Cheney M, Joseph M: Pedicled rhinotomy for clival chordomas invaginating the brainstem. Neurosurg Focus 10(3):E8, 2001

28. Heffelfinger MJ, Dahlin DC, MacCarty CS, Beabout JW: Chordomas and cartilaginous tumors at the skull base. Cancer 32:410-420, 1973

29. Hong Jiang W, Ping Zhao S, Hai Xie Z, Zhang H, Zhang J, Yun Xiao J: Endoscopic resection of chordomas in different clival regions. Acta Otolaryngol 12:1-13, 2008

30. House WF, De la Cruz A, Hitselberger WE: Surgery of the skull base: transcochlear approach to the petrous apex and clivus. Otolaryngology 86:770-779, 1978

31. Hug EB: Review of skull base chordomas: prognostic factors and long-term results of proton-beam radiotherapy. Neurosurg Focus 10(3):E11, 2001

32. Hug EB, Loredo LN, Slater JD, DeVries A, Grove RI, Schaefer $\mathrm{RA}$, et al: Proton radiation therapy for chordomas and chondrosarcomas of the skull base. J Neurosurg 91:432-439, 1999

33. Hug EB, Slater JD: Proton radiation therapy for chordomas and chondrosarcomas of the skull base. Neurosurg Clin $\mathbf{N}$ Am 11:627-638, 2000

34. James D, Crockard HA: Surgical access to the base of skull and upper cervical spine by extended maxillotomy. Neurosurgery 29:411-416, 1991

35. Janecka IP, Sen CN, Sekhar LN, Arriaga M: Facial translocation: a new approach to the cranial base. Otolaryngol Head Neck Surg 103:413-419, 1990

36. Jho HD: Endoscopic endonasal approach to the optic nerve: a technical note. Minim Invasive Neurosurg 44:190-193, 2001

37. Jho HD: Endoscopic transsphenoidal surgery. J Neurooncol 54:187-195, 2001

38. Kimura F, Kim KS, Friedman H, Russell EJ, Breit R: MR imaging of the normal and abnormal clivus. AJNR Am J Neuroradiol 11:1015-1021, 1990

39. Kingdom TT, Delgaudio JM: Endoscopic approach to lesions of the sphenoid sinus, orbital apex, and clivus. Am J Otolaryngol 24:317-322, 2003

40. Laws ER Jr: Transsphenoidal surgery for tumors of the clivus. Otolaryngol Head Neck Surg 92:100-101, 1984

41. Maira G, Pallini R, Anile C, Fernandez E, Salvinelli F, La Rocca LM, et al: Surgical treatment of clival chordomas: the transsphenoidal approach revisited. J Neurosurg 85:784-792, 1996

42. Marton E, Billeci D, Schiesari E, Longatti P: Transnasal endoscopic repair of cerebrospinal fluid fistulas and encephaloceles: surgical indications and complications. Minim Invasive Neurosurg 48:175-181, 2005

43. Menezes AH: Craniovertebral junction neoplasms in the pediatric population. Childs Nerv Syst 10:1173-1186, 2008

44. Mortini P, Mandelli C, Franzin A, Giugni E, Giovanelli M: Surgical excision of clival tumors via the enlarged transcochlear approach. Indications and results. J Neurosurg Sci 45:127-140, 2001

45. Neff B, Sataloff RT, Storey L, Hawkshaw M, Spiegel JR: Chondrosarcoma of the skull base. Laryngoscope 112:134139, 2002

46. Pamir MN, Kilic T, Ture U, Ozek MM: Multimodality management of 26 skull-base chordomas with 4-year mean followup: experience at a single institution. Acta Neurochir (Wien) 146:343-354, 2004
47. Presutti L, Trani M, Alicandri-Ciufelli M, Marchioni D: Exclusive endoscopic removal of a planum sphenoidale meningioma: a case report. Minim Invasive Neurosurg 51:51-53, 2008

48. Prevedello DM, Thomas A, Gardner P, Snyderman CH, Carrau RL, Kassam AB: Endoscopic endonasal resection of a synchronous pituitary adenoma and a tuberculum sellae meningioma: technical case report. Neurosurgery 60:E401, 2007

49. Price JC, Holliday MJ, Johns ME, Kennedy DW, Richtsmeier WJ, Mattox DE: The versatile midface degloving approach. Laryngoscope 98:291-295, 1988

50. Roberti F, Sekhar LN, Jones RV, Wright DC: Intradural cranial chordoma: a rare presentation of an uncommon tumor. Surgical experience and review of the literature. J Neurosurg 106:270-274, 2007

51. Samii A, Gerganov VM, Herold C, Hayashi N, Naka T, Mirzayan MJ, et al: Chordomas of the skull base: surgical management and outcome. J Neurosurg 107:319-324, 2007

52. Schwartz TH, Fraser JF, Brown S, Tabaee A, Kacker A, Anand VK: Endoscopic cranial base surgery: classification of operative approaches. Neurosurgery 62:991-1005, 2008

53. Seifert V, Raabe A, Zimmermann M: Conservative (labyrinthpreserving) transpetrosal approach to the clivus and petroclival region-indications, complications, results and lessons learned. Acta Neurochir (Wien) 145:631-642, 2003

54. Sekhar LN, Janecka IP, Jones NF: Subtemporal-infratemporal and basal subfrontal approach to extensive cranial base tumours. Acta Neurochir (Wien) 92:83-92, 1988

55. Sekhar LN, Nanda A, Sen CN, Snyderman CN, Janecka IP: The extended frontal approach to tumors of the anterior, middle, and posterior skull base. J Neurosurg 76:198-206, 1992

56. Sen CN, Sekhar LN: An extreme lateral approach to intradural lesions of the cervical spine and foramen magnum. Neurosurgery 27:197-204, 1990

57. Sen CN, Sekhar LN: The subtemporal and preauricular infratemporal approach to intradural structures ventral to the brain stem. J Neurosurg 73:345-354, 1990

58. Sen CN, Sekhar LN, Schramm VL, Janecka IP: Chordoma and chondrosarcoma of the cranial base: an 8-year experience. Neurosurgery 25:931-941, 1989

59. Solares CA, Fakhri S, Batra PS, Lee J, Lanza DC: Transnasal endoscopic resection of lesions of the clivus: a preliminary report. Laryngoscope 115:1917-1922, 2005

60. Stevenson GC, Stoney RJ, Perkins RK, Adams JE: A transcervical transclival approach to the ventral surface of the brain stem for removal of a clivus chordoma. J Neurosurg 24:544-551, 1966

61. Tamaki N, Nagashima T, Ehara K, Motooka Y, Barua KK: Surgical approaches and strategies for skull base chordomas. Neurosurg Focus 10(3):E9, 2001

62. Webb-Myers R, Wormald PJ, Brophy B: An endoscopic endonasal technique for resection of olfactory groove meningioma. J Clin Neurosci 15:451-455, 2008

63. Zhu W, Mao Y, Zhou LF, Zhang R, Chen L: Combined subtemporal and retrosigmoid keyhole approach for extensive petroclival meningiomas surgery: report of experience with 7 cases. Minim Invasive Neurosurg 51:95-99, 2008

Manuscript submitted August 15, 2008.

Accepted October 2, 2008.

Please include this information when citing this paper: published online Month Day, Year; DOI: 10.3171/2008.10.FOC08194.

Address correspondence to: Giorgio Carrabba, M.D., Division of Neurosurgery, Toronto Western Hospital, University of Toronto, 399 Bathurst Street, 4th Floor, Toronto, Ontario M5T 2S8, Canada. email: giorgiocarrabba@yahoo.it. 